\title{
Spatial variation in contraceptive use in Bangladesh: Looking beyond the borders
}

\author{
Sajeda Amin \\ Population Council \\ Alaka Malwade Basu \\ Rob Stephenson
}

Follow this and additional works at: https://knowledgecommons.popcouncil.org/departments_sbsr-pgy

Part of the Demography, Population, and Ecology Commons, Family, Life Course, and Society Commons, and the International Public Health Commons How does access to this work benefit you? Let us know!

\section{Recommended Citation}

Amin, Sajeda, Alaka Malwade Basu, and Rob Stephenson. 2000. "Spatial variation in contraceptive use in Bangladesh: Looking beyond the borders," Policy Research Division Working Paper no. 138. New York: Population Council. Version of record: https://doi.org/10.1353/dem.2002.0014 


\section{Spatial Variation in Contraceptive Use in Bangladesh: Looking Beyond the Borders}

Sajeda Amin
Alaka M alwade Basu
Rob Stephenson

2000 No. 138 


\title{
Spatial Variation in Contraceptive Use in Bangladesh: Looking Beyond the Borders
}

\author{
Sajeda Amin \\ Alaka Malwade Basu \\ Rob Stephenson
}

Alaka Malwade Basu is Senior Research Associate, Cornell University, Ithaca. Sajeda Amin is Associate, Population Council, New York. Rob Stephenson is Research Fellow in Reproductive Health, Department of Social Statistics, University of Southampton.

Communications should be addressed to Sajeda Amin, Associate, Policy Research Division, Population Council, One Dag Hammarskjold Plaza, New York, NY 10017 (email: samin@popcouncil.org) 


\begin{abstract}
In this paper, an analysis is made of spatial patterns of contraceptive use in Bangladesh and the contiguous state of West Bengal in India in order to promote a more complete understanding of social change. Earlier analysis found strong evidence of higher contraceptive prevalence in districts of Bangladesh that border Bengali-speaking districts of India. Moreover, analysis of past fertility decline in Europe revealed that shared language played a critical role. Using multilevel analysis to control for variations in individual- and household-level correlates and mapping districts that deviate considerably from their regional averages, the present analysis highlights an important role for cross-border influences only in districts that share the same language across the border. Both in Bangladesh and in West Bengal, the districts that are positive outliers in contraceptive use hug the Bangladesh-West Bengal border. Maps show that the positive outliers disregard international borders and form a contiguous band in a manner that suggests a common-cause explanation of fertility decline.
\end{abstract}

This material may not be reproduced without written permission from the authors. 
The convention in much of contemporary demography is to treat political boundaries as markers of many other characteristics of a population. This approach makes sense when one is trying to understand the impact on demographic behavior of such factors as government policy, because government policy is by definition limited to the political unit over which a government has control. ${ }^{1}$

Government policy is only one determinant of individual behavior, however. The literature has always emphasized that demographic behavior as well as the changes in attitudes that are required for alteration of such behavior hinge also on the socioeconomic and cultural circumstances of a population and the changes in these circumstances. Socioeconomic change may be related to one's nation of residence, especially because so much of such change is driven by policy or at least by changes in the immediate environment. The "culture" that a population inhabits, however, may not respect political boundaries as easily as do factors such as family planning programs or economic development, because political boundaries in most parts of the world are of recent origin and change frequently, whereas what we refer to as culture tends to have developed over a far longer span of time.

Cultural explanations for reproductive behavior that are derived from historical sources in general and on the European Fertility Project in particular are clearly based on acceptance of the cultural irrelevance of the nation-state. Indeed, the relative unimportance of political boundaries in the historical evidence is treated as evidence in support of cultural theories of reproductive behavior. The importance of language rather than of political boundaries in the onset of the fertility transition in present-day Belgium (Lesthaeghe, 1977), for example, has been used to develop what are called "diffusion" theories of fertility change, in which the spread of information and of new attitudes that a common language facilitates is seen as an important determinant of behavioral change.

In analyses of the modern world, however, culture continues to be seen as a national or subnational trait. Cultural maps may not coincide with political maps, and such factors as language and communication across a common language may continue to be important influences on behavior even if the language is shared across political boundaries. In this paper, we acknowledge the importance of language by looking at the role a common language plays in introducing some commonalities in reproductive behavior between population groups that do not share a political or policy environment. 
The common language examined here is Bengali, and the politically distinct but culturally similar groups that share this language and are the focus of this paper are the people of Bangladesh and of the state of West Bengal in India. As we discuss elsewhere (Basu and Amin, 2000), both of these populations are characterized by a strong sense of linguistic identity, an identity that often overwhelms political and religious differences, facilitates the spread of information across these political and religious barriers, and often provides similar motivations for reproductive behavior by supporting similar attitudes to life in general.

After identifying statistical commonalities in the reproductive behavior of Bengalispeaking groups that are separated by a political boundary but are otherwise physically contiguous, we examine some of the ways in which these behaviors may arise, including the diffusion of information and ideas and the experience of common environments of risk. We conclude that the former is more important.

The primary aim, then, is to apply some lessons from the historical experience of Europe to contemporary populations in the developing world while contributing to the growing literature that underlines the importance of social networks, the mass media, and other vehicles for the diffusion of ideas that may lead to reproductive change independently of changes in the objective conditions of life (see for example, Montgomery and Casterline, 1993; Rosero-Bixby and Casterline, 1994; Rutenberg and Watkins, 1997; and Agadjanian, 2000). Although temporal data to investigate this idea in a comprehensive manner are not available, many promising qualitative leads are explored.

To demonstrate the continued methodological value of what has been done with the historical data, we conduct a spatial analysis of contraceptive behavior (as one wellmeasured proxy for the total fertility rate) showing that at least some part of demographic behavior is determined by what one's neighbors do, even if these neighbors are separated from one another by political boundaries. Indeed, the evidence reveals not only that people behave like their neighbors across political boundaries, but also that these very boundaries seem to increase the chances of engaging in innovative behavior (which is one way of characterizing contraceptive use in a poor society). The ability of a common language to facilitate interaction with otherwise heterogeneous groups may, therefore, result in a greater exposure and openness to new forms of behavior. 


\section{BACKGROUND}

An earlier analysis of the pattern of spatial variation in contraceptive use in Bangladesh (Amin, Diamond, and Steele, 1997) leaves the reader with some intriguing questions. This analysis found evidence of considerable spatial variation in contraceptive prevalence within Bangladesh in the aftermath of a rapid fertility decline attributed to increasing contraceptive use. District-level contraceptive practice ranged from 14 percent in Sunamganj to 67 percent in Khulna. Some of this spatial variation is explained by measures of female education and religious practice; considerable variance exists within the country in these social indicators.

A more obviously geographic pattern to the spatial dispersion of levels of contraceptive use is also found, however. The analysis shows a higher concentration of high contraceptive prevalence rates only in the northern and western border districts of the country, while a concentration of low rates appears in the southern and eastern border districts. Based on this initial description of the spatial pattern, the question asked here is whether an understanding of this pattern warrants a look beyond the current political borders of Bangladesh. One explanation could be purely a technological effect of the flow of contraceptive devices or medical services across relatively permeable borders, which would set apart all border districts from nonborder districts. The fact that border districts can be positive as well as negative outliers-that is, showing exceptionally high and exceptionally low contraceptive use, respectively—rules out a purely technological explanation of the flow of goods across borders, however.

Interestingly, the positive outliers in Bangladesh border the state of West Bengal in India. Historical reasons promote an expectation of some commonalities in behavior between Bangladesh and the contiguous state of West Bengal to the west of Bangladesh that could serve as a partial explanation for the spatial patterns found within Bangladesh. Bangladesh shares an extensive border with West Bengal, an Indian state that has much in common with the Bengali population of Bangladesh. Apart from a common political history, Bangladesh and West Bengal share the Bengali language and a language-based ethnic identity. Thus, the two areas share a cultural identity in a way that sets West Bengal apart from the other Indian states that share a border with Bangladesh. 
By exploring spatial variations in fertility, the aim here is to test whether evidence of such language-driven change exists in the rapid fertility decline in Bangladesh, and possibly also in West Bengal. ${ }^{2}$ If such a pattern were to exist, it would illustrate the role of social forces and historical context in influencing the course of contemporary transitions and would temper the strong emphasis placed on programmatic factors used to explain rapid fertility decline in Bangladesh. It would also highlight the role of cultural factors underlying demographic behavior, but with a specification of culture that goes beyond the limited measures of education or women's emancipation typically found in demographic studies.

The next section presents relevant historical and political background contributing to the development of the central hypothesis of this study. The data and the method of analysis are described, followed by a discussion of the highlights of the analysis and the spatial patterns. The paper concludes with an interpretation of the results.

\section{Historical And Political Setting}

The geography of Bangladesh and the cultural characteristics of the states of India that surround Bangladesh are central to the argument developed here. As seen in Map 1, with the exception of the Bay of Bengal to the south and a short border with Myanmar in the southeast, Bangladesh is surrounded by India and shares borders with five Indian states. West Bengal lies to the west, Meghalaya and Assam to the north, Mizoram and Tripura to the east. Among these states, only West Bengal shares a language with Bangladesh. West Bengal and Tripura also share a political history in the sense that prior to 1921, they belonged to the same Greater Bengal State in colonial India (Wolpert, 1993).

The Bengali language is spoken by nearly 200 million people with origins either in Bangladesh or West Bengal. The states of Tripura and Assam have considerable numbers of Bengali speakers who have migrated to these areas from Bengal. The indigenous majority of the population in these states are not Bengali speakers, however. In fact, in Assam and Tripura considerable resentment of the Bengali settlers is evident because they represent competition for indigenous resources. In all of the northeastern states, language and culture are distinctly different from those of the Bengali speakers. 
Map 1 Bangladesh and bordering areas of India

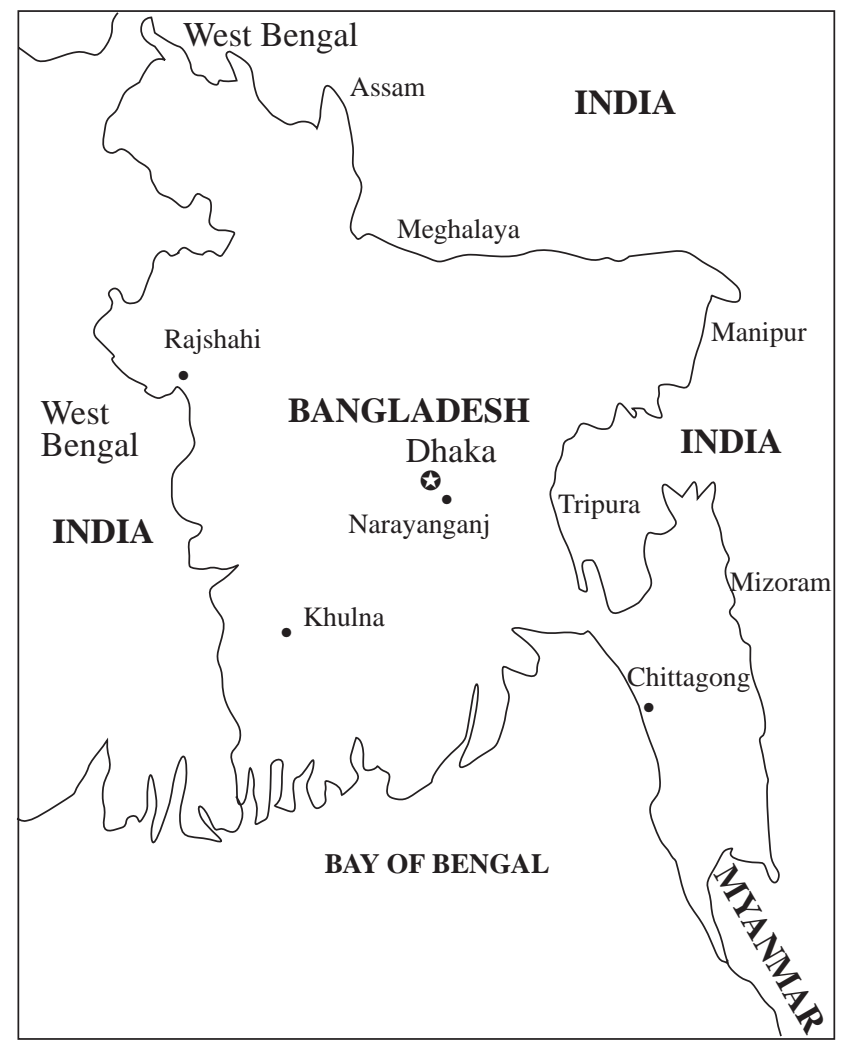

Bangladesh had been part of several larger political units before it became an independent country in 1971: It was East Bengal for a brief period between 1905 and 1912 and East Pakistan between 1947 and 1971. Other than during the brief earlier period, Bangladesh and West Bengal were a united part of Bengal Presidency in colonial India. The borders of Bengal varied at different periods, sometimes including all of the northeastern states and sometimes including states to the west of Bengal, including Bihar and Orissa. With the exception of the periods 1905-12 and after 1947, Calcutta has been the political and economic center of Bengal (Chaudhury, 1995). Thus, a shared administrative and colonial history, which included administrative structures and school systems, may also lie behind the cultural commonalities of Bangladesh and West Bengal. 


\section{DATA}

The data for the present analysis come from the 1992 Indian National Family Health Survey (INFHS) and the 1993-94 Bangladesh Demographic and Health Survey (BDHS). The target population for the surveys are ever-married women aged 13-49 for India and aged 10-49 for Bangladesh. The current analysis uses only the West Bengal data from the INFHS and all of the Bangladesh data. It uses data from the village, household, and individual levels from the three corresponding questionnaires. The hierarchical nature of the data and the potential influence of factors determining contraceptive uptake at multiple levels necessitate a multilevel approach to data analysis.

The sample for the West Bengal data is 4,322 women in 164 primary sampling units (PSU) and 15 districts in urban and rural areas. The sample size in Bangladesh is 7,402 women in 224 primary sampling units and 62 districts in urban and rural areas. Models were estimated for urban and rural areas together and for rural areas separately. The parameter estimates for both models are similar; hence, the models on the full weighted sample are presented here for completeness.

\section{METHOD}

The central question of interest here concerns the spatial variation in contraceptive use. In order to identify those districts that are outliers in terms of contraceptive use, the range of individual- and family-level factors that can influence contraceptive behavior must be controlled. Thus, a method of analysis is required that allows the districtlevel influence on contraceptive use to be modeled while influences on behavior at a number of different levels are controlled. A multilevel modeling strategy provides such a method (Diamond et al., 1997; Amin, Diamond, and Steele, 1997). In addition, both data sets being analyzed are structured hierarchically, with women clustered within primary sampling units that are in turn clustered within districts. This data structure violates the fundamental assumption of independence used in classical regression modeling. Therefore, a multilevel modeling strategy is also required to account for the hierarchical nature of the data (Goldstein, 1995).

A multilevel logistic model using a binary response variable is fitted to determine the factors influencing any form of contraceptive use. In this model, the response vari- 
able is coded as one for all those reporting the current use of any form of contraception (including modern, traditional, and sterilization) and zero for those not currently using any form of contraception. A three-level random effects model is specified to take a form in which individual women (level 1) are nested within primary sampling units (level 2) and then nested within districts (level 3). Separate models are fitted for Bangladesh and West Bengal to facilitate a comparison of the factors influencing contraceptive use and to identify the outlying districts in terms of contraceptive use in each of the areas. The outlying districts identified from a multilevel logistic regression such as the one presented here and multilevel multinomial models (not shown) were found to follow the same pattern. Therefore, this paper presents only the outlying districts identified from the multilevel logistic model of the current use of any form of contraception.

The random effects model can be written as

$$
\operatorname{logit}\left(p_{i j k}\right)=x_{i j k}^{\prime} \beta+u_{j k}+v_{k},
$$

where $\mathrm{P}_{i j k}$ is the probability of using any form of contraception for the $i$ th respondent in the $j$ th PSU in the $k$ th district; $\mathrm{x}^{\prime}{ }_{i j k}$ is a vector of covariates corresponding to the $i$ th respondent in the $j$ th PSU in the $k$ th district; $\beta$ is a vector of unknown parameters; $\mathrm{u}_{j k}$ is the random effect at the PSU level; and $\mathrm{v}_{k}$ is the random effect at the district level. The distribution of the random effects is assumed to be normal, with mean zero and variance $\mathrm{s}_{u}^{2}$. When $\mathrm{s}_{\mathrm{u}}=0$, the model reduces to the ordinary logistic model, indicating that no significant correlation exists in the risk of reporting the current practice of contraception between PSUs and districts. The testing of the null hypothesis $\mathrm{s}_{\mathrm{u}}=0$ against the alternative hypothesis $\mathrm{s}_{\mathrm{u}}>0$ is used to test the significance of random effects terms using a modified likelihood ratio test.

The level-three residuals are used to identify outlying districts of exceptionally high or exceptionally low contraceptive use. Simultaneous confidence intervals are calculated for each of the districts in the data sets, using an adjustment factor calculated for the level-three residuals with a FORTRAN program. These confidence intervals are plotted as high-low plots, and outliers are identified as confidence intervals that do not overlap or do not include zero. This method allows the identification of districts with an exceptionally high use of contraceptives (positive outliers) or with an exceptionally low 
use (negative outliers). It is preferred to a direct mapping of contraceptive prevalence rates because it takes into account a range of other individual, familial, and macro-level factors that can affect contraceptive use and vary spatially, thus acting to confound spatial variations in contraceptive use.

\section{RESULTS AND DISCUSSION}

The analysis was begun by looking at spatial patterns of contraceptive use in Bangladesh and states of India contiguous to Bangladesh. Districts were mapped according to whether they were positive or negative outliers relative to the region to which they belonged. The initial spatial analysis found that only the state of West Bengal had any notable border effects. In all other states, although significant variations were found within the regions studied, no discernible spatial patterns were related to the proximity of the Bangladesh borders. Thus, as observed for the districts within Bangladesh in a previous analysis (Amin, Diamond, and Steele, 1997), it is not proximity to a border per se, but proximity to a border state in which the same language is spoken that appears to make a district a positive outlier. An understanding of the cultural differences between Bangladesh and the northeastern states of India does not lead to expectations of common cause; therefore, the remainder of this analysis focuses on Bangladesh and West Bengal.

Table 1 presents a breakdown of contraceptive method choice for West Bengal and Bangladesh. West Bengal has slightly higher overall contraceptive use. The main difference in the two settings is in the choice of method: Whereas contraception in West Bengal is dominated by sterilization and traditional methods, in Bangladesh temporary modern methods are most prevalent. This variation may be a function of the wider choice of methods and the greater access to these methods provided by home-based service delivery in Bangladesh.

Table 1 also shows the distribution of the primary covariates of contraception. These are broadly similar in the two countries. The variables that have been strongly associated with contraception are respondent's age, education, work status, exposure to media, and sex-specific parity of women. The sample respondents reflect what is generally known about contrasts between West Bengal and Bangladesh: The women in the 
West Bengal sample are slightly more educated, the population in West Bengal is slightly more urban, and a higher proportion of West Bengali women report that they work for cash. These differences are small, however. The most striking contrast between the two populations is that that of West Bengal is predominantly Hindu, whereas the Bangladeshi sample is predominantly Muslim. Differences are also seen in the proportion of women who report that their husbands approve of contraceptive use: A considerably higher proportion of Bangladeshi women reported their husbands' approval, whereas a high proportion of West Bengali women said that they did not know.

A wide range of overall method use is found in West Bengal, from 30 percent in Purulia district to 77 percent in Hugli (data not shown). The range is similarly wide in Bangladesh, as mentioned above. Method-specific rates do not follow the ranking of overall rates. For instance, the lowest uptake of modern methods in West Bengal is in the district of Malda and not in Purulia. In fact, Purulia has a relatively high level of modern-method use. As expected, the lowest levels of traditional method use are found in those districts that report the highest rates of modern-method use. These data may be misleading, however, because some of them may be derived from compositional differences between districts in important determinants such as religion or education that must be taken into account to ensure a pure spatial comparison of the sort presented here.

Table 2 shows that most individual-level effects of these variables on contraceptive use are similar in direction and magnitude. Urban residence appears to have a greater influence in West Bengal than it does in Bangladesh - a result that may be attributable to the strong emphasis on family planning services in rural Bangladesh. Hindus report higher contraceptive use in both places compared with non-Hindus, even though nonHindus are in the minority in West Bengal and are the majority in Bangladesh. The two education variables, that of the respondent and her partner, ideally should be interpreted together because they are likely to be collinear. Respondents' education shows a stronger association with method use in West Bengal ${ }^{3}$ whereas partner's education is statistically significant only in Bangladesh.

The models experimented with a range of socioeconomic indicators at the individual and the PSU level, none of which proved to be significantly associated with contraceptive use. The model presented here shows an index constructed to measure 
Table 1 Percentage distribution of independent variables used in multilevel modelling of Bangladesh and West Bengal data

\begin{tabular}{|c|c|c|}
\hline Variable & Bangladesh & West Bengal \\
\hline \multicolumn{3}{|l|}{ Type of contraception } \\
\hline None & 55.5 & 48.1 \\
\hline Modern & 19.5 & 5.7 \\
\hline Sterilization & 14.1 & 27.5 \\
\hline Traditional & 10.8 & 18.7 \\
\hline \multicolumn{3}{|l|}{ Respondent's age } \\
\hline $13-19$ & 15.8 & 13.1 \\
\hline $20-24$ & 21.9 & 19.8 \\
\hline $25-29$ & 20.8 & 19.7 \\
\hline $30-34$ & 15.2 & 15.2 \\
\hline $35-39$ & 11.9 & 14.0 \\
\hline $40+$ & 14.4 & 18.2 \\
\hline \multicolumn{3}{|l|}{ Religion } \\
\hline Muslim & 87.5 & 27.0 \\
\hline Other & 12.5 & 73.0 \\
\hline \multicolumn{3}{|l|}{ Residence } \\
\hline Urban & 15.9 & 20.8 \\
\hline Rural & 84.1 & 79.2 \\
\hline \multicolumn{3}{|l|}{ Education } \\
\hline None & 57.9 & 53.6 \\
\hline Primary & 29.6 & 38.0 \\
\hline Secondary + & 12.5 & 8.4 \\
\hline \multicolumn{3}{|l|}{ Partner educated } \\
\hline Yes & 58.0 & 64.4 \\
\hline No & 42.0 & 35.6 \\
\hline \multicolumn{3}{|l|}{ Partner approves of contraception } \\
\hline Yes & 81.2 & 45.7 \\
\hline No & 11.8 & 14.3 \\
\hline Doesn't know partner's attitude & 7.1 & 40.0 \\
\hline \multicolumn{3}{|l|}{ Works outside home } \\
\hline Yes & 14.2 & 23.4 \\
\hline No & 85.8 & 76.6 \\
\hline
\end{tabular}


Table 1 (continued)

\section{Variable}

Bangladesh

West Bengal

Caste

Scheduled caste

$\begin{array}{cc}- & 9.3 \\ - & 5.3 \\ - & 85.4\end{array}$

Other

Number of children

0

11.3

12.5

1-2

31.8

36.3

3-4

26.7

27.5

$4+$

30.2

Listens to radio once per week

Yes

46.6

No

62.1

53.4

Watches TV once per week

Yes

11.6

29.6

No

88.4

70.4

Standard-of-living index

Rich

1.3

1.8

Upper middle

4.5

3.1

Middle

14.3

9.9

Lower middle

32.4

36.6

Poor

47.5

48.6

Border status

Nonborder

57.5

27.0

Other border

West Bengal / Bangladesh border

21.3

44.0

- = Not applicable.

standard of living and includes the following variables: source of water; type of fuel used for cooking; main source of lighting; whether a separate room is used for cooking; ownership of livestock and land and various durable goods such as sewing machine, clock, fan, radio, refrigerator, bicycle, car, tractor, or water pump. Response categories for these variables were given a value depending on the desirability of that category 
Table 2 Multilevel logistic modeling of women's reported contraceptive uptake in West Bengal and Bangladesh

Odds ratio

Variable

Respondent's age

13-19

20-24 (r)

25-29

30-34

35-39

$40+$

Religion

Hindu / non-Islamª (r)

Muslim

Other
Bangladesh

$1.03 *$

$1.69 *$

1.00

$1.63 *$

$2.15^{*}$

$2.31^{*}$

$1.72 *$

1.00

$0.66^{*}$

$0.75^{*}$

1.00

$1.21^{*}$

$2.92 *$

1.00

1.00

Urban (r)

Rural

$0.89 *$

$0.50^{*}$

Caste

Scheduled caste

Scheduled tribe

Other (r)

Listens to radio once a week

Yes (r)

No

1.00

1.00

$0.79 *$

$0.81 *$

Watches television once a week

Yes (r)

1.00

1.00

No

$0.89 *$

0.98

Works outside home

Yes (r)

1.00

1.00

No
$0.70^{*}$ 
Table 2 (continued)

Odds ratio

Variable

Bangladesh

West Bengal

Partner approves of contraception

Yes (r)

1.00

1.00

No

$0.45 *$

$0.32 *$

Doesn't know partner's attitude

$0.38 *$

0.33

Number of children

0 (r)

1.00

1.00

1-2

$3.64 *$

$4.35 *$

3-4

$5.39 *$

$4.12^{*}$

$4+*$

$4.62 *$

$2.19 *$

Standard-of-living index

Rich

1.01

1.03

Upper middle

1.02

1.03

Middle (r)

1.00

1.00

Lower middle

0.98

0.94

Poor

0.96

0.91

Border district

Nonborder (r)

1.00

1.00

Other border

0.94

$0.84 *$

West Bengal / Bangladesh border

$1.12 *$

$1.15^{*}$

Partner educated

Yes (r)

1.00

1.00

No

$0.72 *$

0.83

PSU-level random effect (Beta)

$0.301 *$

$0.087 *$

District-level random effect (Beta)

$0.042 *$

$0.037 *$

Constant (Beta) $-1.432$ $-1.127$

*Significant at $\mathrm{p}<.005 . \quad-\quad=$ Not applicable. $\quad(\mathrm{r})=$ Reference category.

${ }^{a}$ The reference category in West Bengal is Hindu. The reference category in Bangladesh is non-Islam.

with reference to the rest. For example, having water piped into the house has a higher score than does having to use a public well. Variables were weighted and then summed so that those that were rare received a higher weight. The standard-of-living index was then converted into a four-category variable. Socioeconomic status measures are not 
significant in predicting contraceptive use in either West Bengal or Bangladesh. Models were estimated entering the socioeconomic index at the individual level as well as at the PSU level in a random slopes model that allowed the estimation of effects between clusters. Another variable used was the proportion of households owning agricultural land in the cluster. These effects did not prove to be significant predictors and have not been shown.

A three-category variable indicating position of the district relative to the border shows an important spatial pattern. Districts were further divided to indicate whether they bordered a same-language state or a different-language state, and both of these border categories were compared with nonborder states. Women who lived in districts that bordered a same-language state were significantly more likely to use contraceptives than were women living in nonborder states in Bangladesh and West Bengal. The other border districts, ones that do not share a language across the border, have significantly lower levels of contraceptive uptake in West Bengal, but the parameter estimate in Bangladesh is not statistically significant. This finding is significant only for West Bengal, however. The language-border effects should likely be interpreted taking these other border effects into account. Because metropolitan areas in both Bangladesh and West Bengal are in nonborder locations, the border effect, in the absence of a language-culture effect, would be to reduce the probability of contraceptive uptake because of the remoteness of the border regions from metropolitan centers. Because all of the border states are equally remote in this regard, the fact is striking that the Bangladesh-West Bengal border has such a strong influence on contraceptive use.

Map 2 depicts shared language-border effects. In order to show the spatial pattern associated with proximity to a same-language border state, outliers are identified using models that exclude the border variable (which explains much of the district-level random effect). Districts of Bangladesh and West Bengal are shown according to whether they are outliers in terms of prevalence of contraceptive use after all of the other abovementioned correlates are considered. Outliers are identified according to the criteria mentioned in the Method section. In general, the positive and negative outlier districts hug the borders in both places. In Bangladesh, the positive outliers lie in the west, whereas in West Bengal they lie toward the east, that is, along the shared border between the two 


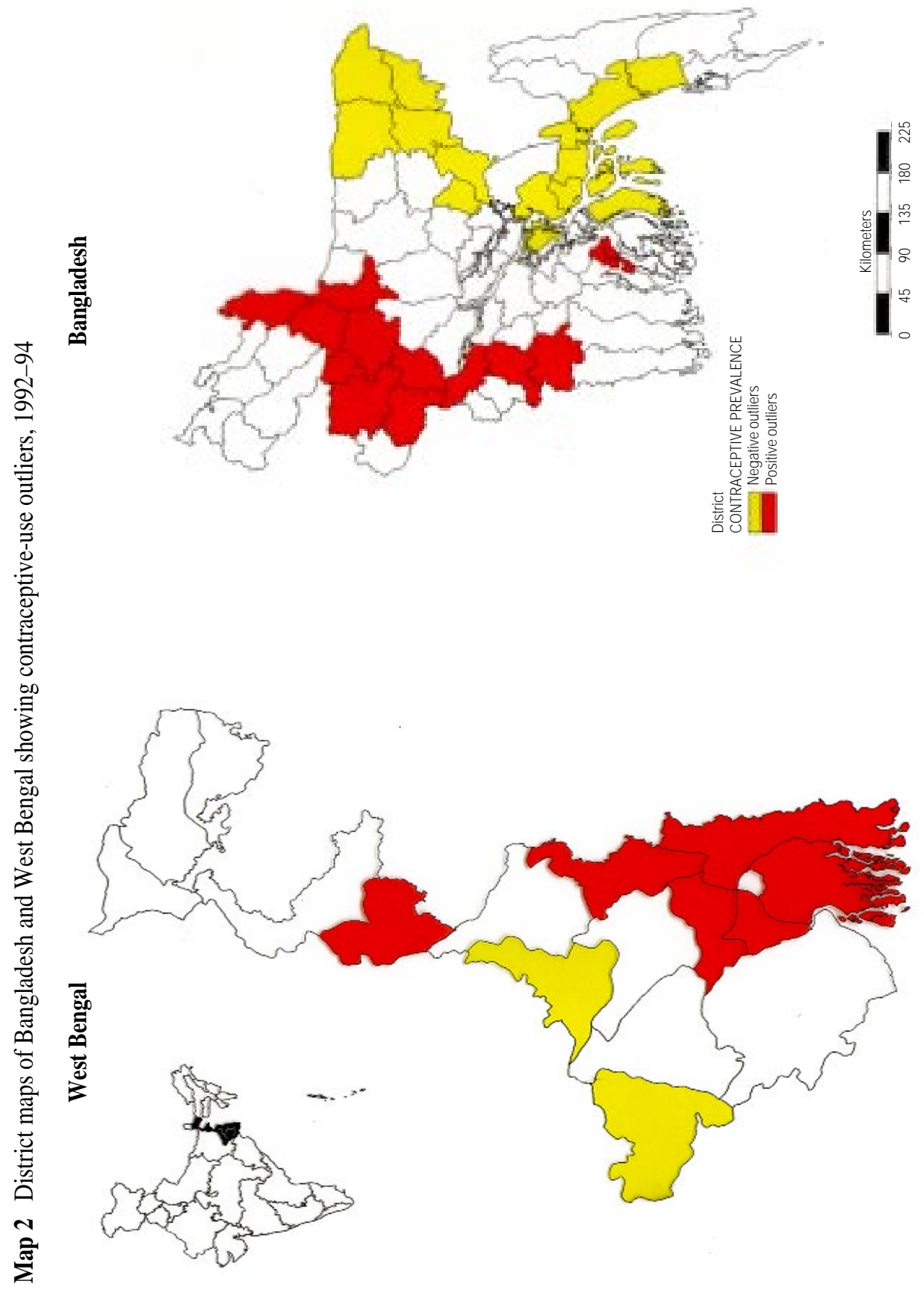


regions. Map 3 merges the same data. The positive outliers in both Bangladesh and West Bengal form a contiguous band that appears to be uninterrupted by the political borders, a striking pattern. The negative outliers in both regions hug the non-Bengali-speaking bordering states. The districts that do not differ significantly from the national average are in the middle of the region and are shown in white on these maps.

\section{INTERPRETING SPATIAL VARIATIONS}

The spatial variation of contraceptive use in Bangladesh reported by Amin, Diamond, and Steele (1997) seems to be a part of a larger geographic picture. The statistically significant finding that bordering districts of Bangladesh and West Bengal that share the same language are contraceptive outliers emphasizes the role of common cause coupled with what may be a process of contagion-type diffusion. The role of language may be rooted in a set of historical factors that predispose the inhabitants of these border districts to more innovative behavior. The negative outliers hug the non-Bengali-speaking borders of Bangladesh and the state of West Bengal, suggesting that change is slowest where little opportunity exists for exposure to new ideas conveyed through a shared language across political boundaries.

A fuller interpretation of these spatial patterns requires consideration of a number of historical and contextual factors, however. Two categories of such factors must be examined: (a) factors conducive to promoting social change that are, therefore, important in enhancing similarities in reproductive behavior on both sides of the border, such as language, culture, and cross-border communication; and (b) factors retarding social change and thus differentiating border districts that share a common language from nonborder districts, such as religious and social conservatism and resistance to development initiatives.

\section{Language}

The role of language is clear because the evidence shows that border proximity per se matters less than the proximity to a border where the same language is spoken on both sides. A common language promotes familiarity and, therefore, probably facilitates greater exchange, but a common language is not enough to guarantee innovative behav- 
Map 3 District merged map of Bangladesh and West Bengal showing contraceptive-use outliers, 1992-94

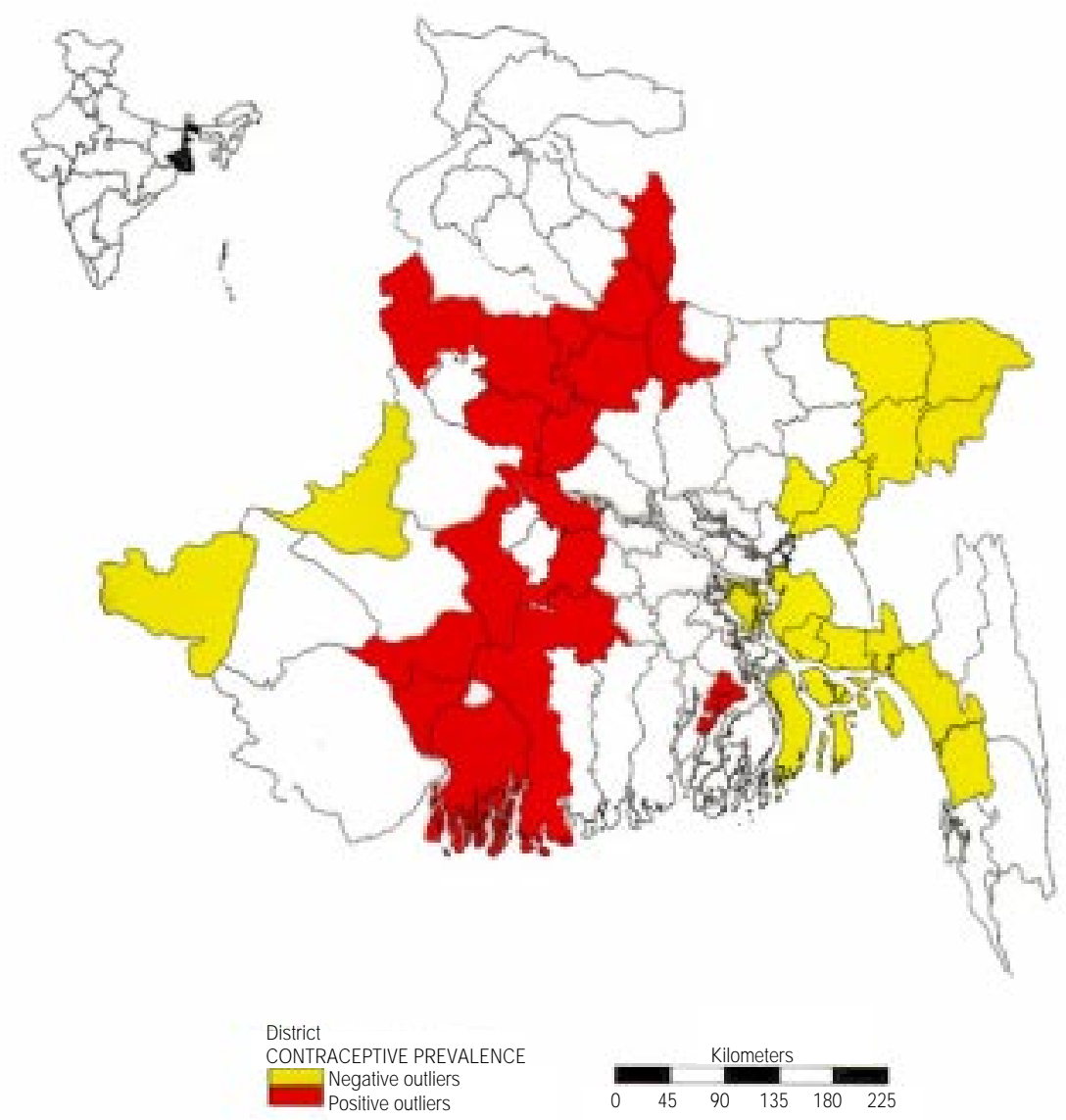

ior. The specific historical context, and in particular the role of language, in conferring a common identity is important in promoting greater interaction and exchange across political borders. In the case considered here, Bengali is the language common to both sides of the Bangladesh-West Bengal border, and speaking Bengali confers upon residents a common historical and cultural identity and facilitates the spread of ideas across two politically separated groups. 


\section{Culture}

We propose that the role that culture plays in demographic behavior is particularly strong in same-language border districts. In the case of Bengal, as with that of the European fertility decline, language is an important marker of culture at a descriptive as well as at a functional level. Apart from the immediate effects on cross-border communication and migration, political and national transitions were strong influences on identity and particularly on the role of language in defining identity. The creation of Pakistan and India as separate Muslim and Hindu states was based on the premise that religion would define each country's identity. In Pakistan, partition was followed by the adoption of policies that clearly preserved this role for Islam, implying that other identities would be dominated by religion. One example was the choice of Urdu as a national language, even though the majority did not speak it, on the grounds that it was the most Islamic of the major languages spoken in Pakistan. This idea proved to be untenable in Bangladesh because Bengalis were more strongly committed to an identity based on their language rather than on their religious identity. Urdu was rejected in favor of the neutral choice of English as the official language.

Clearly, there are specific historical and political reasons why the Bengali ethnic identity may be particularly potent in influencing behavioral change. As Anderson (1986) speculates, having a common language is not the only factor that eases communication between populations; identification with a linguistic group may be important in encouraging interaction with groups that share a language identity and in developing a set of shared values and attitudes as well. This sense of language identity certainly exists in both Bangladesh and West Bengal (see, for example, Basu and Amin, 2000); it explains, in part, why the Bengali-speaking populations of Bangladesh and West Bengal who have lived under political regimes hostile to each other for a considerable part of the last 50 years have enjoyed continuing cross-border contact and exposure at a popular level through migration, the radio, the printed media, and more recently, through television. A fair amount of travel across the shared border apart from migration, has also occurred because the border has remained relatively open.

Language as a way of defining ethnic identity in this kind of political context can influence behavior in several ways. First, by being shared across political borders, it 
offers the potential for greater awareness of the world outside national boundaries. In the case of Bangladesh, the considerable family planning propaganda that was commonplace in India in the 1960s and 1970s may have been a direct influence, although modernizing influences of the more urbanized West Bengal are likely to have had a greater effect in this context. Second, the emergence of new national and political identities in close proximity sharing a common language may have resulted in more intense evaluation and scrutiny of such new ideas as family planning than they would have otherwise received. The politics of identity, especially the notion of emerging hybrid competing identities, may have created a stronger tendency not only to be open to new behaviors and practices but also to develop a capacity to evaluate and adapt new influences on culture and behavior. The two populations examined here, especially those segments living close to the shared border, may therefore have a heightened capacity to evaluate and accept new influences, such as those being offered by the family planning program vis-à-vis contraception.

\section{Cross-border communication}

Historical migration patterns, particularly those following the 1947 partition, should also be considered as a factor contributing to the general level of openness in the border districts. Partition entailed large-scale migration of Hindus from East Pakistan to West Bengal and of Muslims from West Bengal to East Pakistan, and these migrations affected the border districts of West Bengal and Bangladesh mostly in terms of where the migrants settled. ${ }^{4}$ Although communal riots occurred in Bengal, they were not nearly so severe as those in the western border areas of India, a fact that is often interpreted as reflecting the more harmonious relations between the two groups in Bengal compared with other parts of the subcontinent. In Bengal, post-partition migration was not associated with trauma and bloodshed as great as in other parts of India. Relevant to its contribution to cross-border interaction, the migration occurred as a gradual process and continued until the mid-1960s, whereas in other parts of India the post-partition migration waves were brutal and bloody, but short. Therefore, one significant difference can be seen between the two wings of Pakistan: Whereas the flow of refugees across the Punjab and Sindh borders in the West ended in the 1940s, also effectively closing further cross- 
border communication, in Bangladesh they continued into the 1960s when a war between India and Pakistan closed border communication for approximately six years.

In 1971, another war, culminating in the formation of a separate country, Bangladesh, by the Bengalis of Pakistan, resulted in a temporary mass migration of Bengali refugees across the border fleeing persecution by the armed forces of Pakistan, again affecting the border districts most. Between March and December of 1971, while the war for independence was being fought, an estimated 10 million refugees fled to India, the majority going to West Bengal, but a significant proportion migrating to other states as well. After independence, thanks to a well-coordinated transportation effort by the Indian government and a strong policy statement that Bangladeshis would not be resettled as refugees, but would be considered illegal migrants, most of the refugees are said to have returned to Bangladesh after the war. One official report estimates that more than 7 million refugees from East Pakistan (Bangladesh) were in West Bengal in 1971 (Franda, 1982).

More recent Government of India estimates (see Banerjee et al., 1999) suggest that such temporary migration continued after 1971; these estimates report that between 1972 and 1993, about 4 million people arrived in India from Bangladesh, of which all but 800,000 eventually returned. Even if these figures are only rough approximations (as they are likely to be), they suggest a large potential for the movement of ideas and information across borders in both directions. As Banerjee et al. (1999: 2,449) comment, "Convictions about the sanctity of the border are weaker in this region than anywhere else in India."

In addition to the movement of people, other conduits of cross-border exchange exist. Once it became an independent state in 1971, trade opened up between Bangladesh and the rest of the world as a matter of national policy, so that Bangladeshi markets became a channel for foreign goods smuggled into West Bengal, which remained under a closed trade regime for some time (Faaland and Parkinson, 1976). This intense (frequently illegal) trade across borders has not stopped since the opening up of the Indian economy in the early 1990s. According to a detailed survey conducted by the National Council of Applied Economic Research (Choudhuri, 1990), a change in the direction of the flow of goods across the border may have occurred. Price differentials now favor movement of goods from West Bengal to Bangladesh. The sophistication and organization of these trade channels and the vast network of individuals that they appear to involve must, in principle, also contribute to the flow of ideas and information as well. 
Following its war of independence, Bangladesh was the recipient of large amounts of foreign aid, and it became the focus of innumerable social and developmental experiments supported by such funding. One example is the much-publicized Grameen Bank's microcredit scheme for impoverished women. These programs are viewed with cautious interest in West Bengal, particularly because they represent development strategies that are contrary to the leftist politics of the West Bengal government. The extent of Bangladesh's dependence on external aid and the role of its nongovernmental agencies are viewed with a combination of interest and suspicion in the West Bengal press.

\section{Religious and social conservatism}

Amin, Diamond, and Steele (1997) developed a means of measuring religious conservatism showing that contraceptive use was significantly associated with frequent religious practice and that some of the spatial variation in contraceptive use could be explained by measures of community-level religiosity and education. This variable, like the role of NGOs, is likely to be related to the willingness of a district or village to accept and innovate in the area of contraceptive use and in other matters that represent a departure from traditional practices. Levels of education also vary considerably by district and have been shown to have multilevel effects on contraceptive use (Amin, Diamond, and Steele, 1997). Surprisingly, however, educational levels do not correspond to the pattern of religious conservatism, and although they explain the spatial variation in contraceptive use on their own, education does not follow the same spatial pattern as does religious conservatism. The positive outliers have high and low education levels, as do the negative outliers. Sherpur district in Bangladesh has among the lowest educational attainment and the highest contraceptive use of all districts in the country.

\section{CONCLUSION}

In highlighting the role of local history in explaining contraceptive behavior by means of spatial analysis, this paper focuses on contraceptive use, because of the relative availability of good data. Similar arguments might be developed for adoption of any innovation, however. Adoption of agricultural innovations would probably show similar patterns. The analysis and data presented here suggest a historically and spatially specific argument for explaining the timing and onset of fertility decline in Bangladesh and 
West Bengal. By extending the analysis beyond current political borders in a comparison that highlights the similarity of contraceptive patterns between these two regions, we reveal the incompleteness of analyses that restrict themselves to present political structures and purely contemporary conditions and policies. For a variety of pragmatic reasons, most analyses tend to look at national units, but the findings presented here suggest strongly that an historical analysis that also places exclusive emphasis on the modern nation-state may be missing an important part of the explanation of demographic change.

\section{Notes}

1 This tendency, of course, ignores the many "extraterritorial" influences on government policy itself, especially in these days of substantial international funding and ideological pressures on national governments.

2 The 1993-94 National Family Health Survey provided the first reliable estimates of fertility and contraceptive use in West Bengal, showing levels comparable to those in Bangladesh. Data are also available for the states contiguous to Bangladesh and West Bengal- the northeastern states of Bihar and Orissa. The data do not permit identification of the time of onset of the fertility decline in the Indian states, however. Some crude vital registration data suggest an earlier onset of the decline in West Bengal. Thus, the pace of decline in West Bengal is not as rapid as that in Bangladesh.

3 This is the case for those who have primary schooling. We discount the relationship for groups with higher education because the proportions of women in these categories are small in Bangladesh.

4 Although many Bengali-speaking migrants settled in the districts closest to the border, the handful of non-Bengali migrants who moved to East Pakistan from Eastern India settled in the urban areas of Dhaka and Chittagong. The migration of Hindus from East Pakistan was considerably different in nature and was not as complete or as harsh as the migration of Hindus and Sikhs from West Pakistan. Franda (1982) argues that this difference may have been a result in part of central 
government policy toward refugee resettlement: Bengali Hindus were not offered the same kind of resettlement benefits as were Punjabi or Sindhi Hindus and Sikhs.

\section{References}

Agadjanian, Victor. 2000. "Religion, social milieu and the contraceptive revolution in sub-Saharan Africa." Paper presented at the annual meeting of the Population Association of America, Los Angeles, 23-25 March.

Anderson, Barbara A. 1986. "Regional and cultural factors in the decline of marital fertility in Europe." In Ansley J. Coale and Susan C. Watkins (eds.), The Decline of Fertility in Europe. Princeton: Princeton University Press, pp. 293-313.

Amin, Sajeda, Ian Diamond, and Fiona Steele. 1997. "Contraception and religiosity in Bangladesh.” In Gavin W. Jones, Robert M. Douglas, John C. Caldwell, and Rennie M. D'Souza (eds.), The Continuing Demographic Transition. Oxford: Oxford University Press, pp. 268-289.

Banerjee, P., S. Hazarika, M. Hussain, and R. Sammadar. 1999. "Indo-Bangladesh crossborder migration and trade." Economic and Political Weekly, 34(36): 2,449-2,451.

Basu, Alaka Malwade and Sajeda Amin. 2000. "Some preconditions for fertility decline in Bengal: History, language identity, and an openness to innovations." Population and Development Review 26(4). Also published as Population Council Policy Research Division Working Paper no. 142.

Choudhuri, Sukanta (ed.). 1990. Calcutta, The Living City. Calcutta: Oxford University Press.

Chaudhury, S.K. 1995. "Cross-border trade between India and Bangladesh." National Council of Applied Economic Research, Working Paper no. 58. In Ranabir Samaddar, The Marginal Nation: Transborder Migration from Bangladesh to West Bengal. New Delhi: Sage Publications.

Diamond Ian, Pete Tonkin, A.P.M. Shafiqur Rahman, and Sk. Ali Noor. 1997. "Spatial variation in contraceptive method use in Bangladesh." In Andrew Kantner, Al- 
Sabir Ahmed, and Chakraborty Nitun (eds.), Bangladesh Demographic and Health Survey Extended Analysis. Dhaka: NIPORT, pp. 136-157.

Faaland, Just and John R. Parkinson. 1976. Bangladesh: The Test Case of Development. Boulder, CO: Westview Press.

Franda, Marcus. 1982. Bangladesh: The First Decade. New Delhi: South Asian Publishers.

Goldstein, Harvey. 1995. Multi-level Statistical Model: Second Edition. Kendall's Library of Statistics Three. London: S. Arnold.

Lesthaeghe, Ron. 1977. The Decline of Belgian Fertility, 1800 to 1970. Princeton: Princeton University Press.

Montgomery, Mark R. and John B. Casterline. 1993. "The diffusion of fertility control in Taiwan: Evidence from pooled cross-section time-series models." Population Studies 47(3): 457-479.

Rosero-Bixby, Luis and John B. Casterline. 1994. "Interaction diffusion and fertility transition in Costa Rica." Social Forces 73(2): 435-462.

Rutenberg, Naomi and Susan Cotts Watkins. 1997. "The buzz outside the clinic: Conversations and contraception in Nyanza Province, Kenya." Studies in Family Planning 28(4): 290-307.

Wolpert, Stanley. 1993. A New History of India, 4th Edition. New York: Oxford University Press. 


\section{POLICY RESEARCH DIVISION WORKING PAPERS}

Recent Back Issues

1998

*106 Sajeda Amin and Gilda Sedgh, "Incentive schemes for school attendance in rural Bangladesh."

107 Martin Brockerhoff and Paul Hewett, "Ethnicity and child mortality in sub-Saharan Africa."

108 Ann E. Biddlecom and Bolaji M. Fapohunda, "Covert contraceptive use: Prevalence, motivations, and consequences."

109 John Bongaarts and Griffith Feeney, "On the quantum and tempo of fertility."

110 Barbara S. Mensch, Daniel Bagah, Wesley H. Clark, and Fred Binka, "The changing social environment for adolescents in the Kassena-Nankana District of northern Ghana: Implications for reproductive behavior."

111 Martin Brockerhoff and Ann Biddlecom, "Migration, sexual behavior, and HIV diffusion in Kenya."

112 Zeba A. Sathar and John B. Casterline, "The onset of fertility transition in Pakistan."

113 Geoffrey McNicoll, "Government and fertility in transitional and posttransitional societies."
*114 John Bongaarts, "Fertility and reproductive preferences in post-transitional societies."

115 Fiona Steele, Sajeda Amin, and Ruchira T. Naved, "The impact of an integrated micro-credit program on women's empowerment and fertility behavior in rural Bangladesh."

*116 Cynthia B. Lloyd, Barbara S. Mensch, and Wesley H. Clark, "The effects of primary-school quality on the educational participation and attainment of Kenyan girls and boys."

*117 Sajeda Amin and Cynthia B. Lloyd, "Women's lives and rapid fertility decline: Some lessons from Bangladesh and Egypt."

118 James F. Phillips and Mian Bazle Hossain, "The impact of family planning household service delivery on women's status in Bangladesh."

*119 Mark R. Montgomery and John B. Casterline, "Social networks and the diffusion of fertility control."

* No longer available 
*120 John Bongaarts, "The fertility impact of changes in the timing of childbearing in the developing world."

*121 James F. Phillips, Wendy L. Greene, and Elizabeth F. Jackson, "Lessons from community-based distribution of family planning in Africa."

122 Mark R. Montgomery, "Mortality decline and the demographic response: Toward a new agenda."

*123 Mark R. Montgomery, Mary ArendsKuenning, and Cem Mete, "The quantity-quality transition in Asia."

124 Barbara S. Mensch, Wesley H. Clark, Cynthia B. Lloyd, and Annabel S. Erulkar, "Premarital sex and school dropout in Kenya: Can schools make a difference?"

125 John Bongaarts and Rodolfo A. Bulatao, "Completing the demographic transition."

126 Geoffrey McNicoll, "Population weights in the international order."
127 Cynthia B. Lloyd, Carol E. Kaufman, and Paul Hewett, "The spread of primary schooling in sub-Saharan Africa: Implications for fertility change."

128 John B. Casterline, "The onset and pace of fertility transition: National patterns in the second half of the twentieth century."

129 Mark R. Montgomery, Michele Gragnolati, Kathleen Burke, and Edmundo Paredes, "Measuring living standards with proxy variables."

130 Bamikale Feyisetan and John B. Casterline, "Fertility preferences and contraceptive change in developing countries."

131 Martin Brockerhoff, "Urban growth in developing countries: A review of projections and predictions."

132 Omaima El-Gibaly, Barbara Ibrahim, Barbara S. Mensch, and Wesley H. Clark, "The decline of female circumcision in Egypt: Evidence and interpretation."

* No longer available 
133 Mary Arends-Kuenning and Sajeda Amin, "The effects of schooling incentive programs on household resource allocation in Bangladesh."

134 John Bongaarts and Charles F. Westoff, "The potential role of contraception in reducing abortion."

135 John B. Casterline and Steven W. Sinding, "Unmet need for family planning in developing countries and implications for population policy."

136 Carol E. Kaufman, Thea de Wet, and Jonathan Stadler, "Adolescent pregnancy and parenthood in South Africa."
137 Valerie L. Durrant and Zeba A. Sathar, "Greater investments in children through women's empowerment: A key to demographic change in Pakistan?"

138 Sajeda Amin, Alaka Malwade Basu, and Rob Stephenson, "Spatial variation in contraceptive use in Bangladesh: Looking beyond the borders." 